\title{
Problems and pitfalls in modern competency-based laparoscopic Training
}

\author{
M. P. Schijven • W. A. Bemelman
}

Received: 1 November 2009/Accepted: 3 November 2010/Published online: 7 February 2011

(c) The Author(s) 2011. This article is published with open access at Springerlink.com

Traditionally, surgical training has been a matter of apprenticeship. The surgical trainee learned to perform surgery under the supervision of a trained surgeon until he or she was believed capable of performing surgery independently. The opinion of the supervising surgeon was about the only informal standard that had to be met-a standard hard to define, second to none, but the hand of God himself, as perceived both within and without surgical societies. This is illustrated by literature, in which a capital for "Surgeon" is allowed in both ancient and recent publications [1-3].

At the beginning of the new millennium, a paradigm shift in medical education thinking became apparent. Public opinion developed into a powerful force, a force affected by messages such as the rate of iatrogenic complications in U.S. hospitals. If extrapolated to the airline industry, this would be the equivalent of three large jet crashes every two days [4].

In addition, patient safety and quality-of-care movements together with forces from technological innovation and governmental attention demanded safer and more transparent health care systems, systems whose very foundation must be build on the principle of accountability, hence, systems able and actively seeking for self-reflection of performance. Consequently, these must be systems that actively seek for opportunities to improve medical education and thereby ultimately create optimal conditions for near-future patient care [5-7].

From the European Association for Endoscopic Surgery Publication Committee.

M. P. Schijven ( $₫) \cdot$ W. A. Bemelman Department of Surgery, Academic Medical Center, University of Amsterdam, P.O. Box 22700, 1100 DE Amsterdam, Netherlands

e-mail: m.p.schijven@amc.uva.nl
The combination of the aforementioned forces, all stressing the need to reform medical education, led to the development of standards for physician competence.

\section{Competency frameworks}

Surgical institutions and organizations were challenged to define the competencies required by the public and medical educators, competencies needed by surgeons to best meet the needs of their patients. The Royal College of Physicians and Surgeons of Canada (RCPSC) was the first organization to take up this challenge systematically. This resulted in a competency framework design called the Canadian Medical Education Directions for Specialists (CanMEDS) project [7].

The focus of CanMEDS is on articulating a comprehensive definition of the competencies needed for medical education and practice [8]. In 1996, the Council of the RCPSC formally accepted CanMEDS as the foundational framework for its educational mission.

The CanMEDS framework is organized around seven roles: medical expert (central role), communicator, collaborator, health advocate, manager, scholar, and professional. CanMEDS makes explicit the abilities long recognized in highly skilled physicians and constantly updates them for today's-and tomorrow's-medicine. As such, the CanMEDS framework was extensively reviewed, updated, and launched in September 2005.

The CanMEDS competencies currently are integrated into the Royal College's accreditation standards, objectives of training, final in-training evaluations, exam blueprints, and the maintenance-of-certification program. Several countries, including Denmark, the Netherlands, Australia 
and New Zealand, have used the CanMEDS competence framework as a model for specialist education.

With the advent of new frameworks for defining the outcomes of surgical training, such as CanMEDS from the RCPSC and the newer six-role-based competency framework from the Accreditation Council for Graduate Medical Education (ACGME) in the United States, approved by the ACGME Board in 2007, the focus of surgical training has been broadened [9].

In fact, medical boards around the world face the challenge of creating competency-based postgraduate training programs; driven by recent legislations [10]. Consequently, training programs are rewritten largely according to CanMEDS or some other competency-based medical education framework $[11,12]$.

\section{Competency in modern laparoscopic surgery}

The aim of a modern surgical residency program must be to produce competent professionals in a safe and pedagogically efficient environment [13]. The traditional approach based on the apprenticeship model is not only obsolete; it simply cannot accommodate the skills required in performing laparoscopic surgery [14]. Recent history has made this clear.

The first reported laparoscopic cholecystectomy was performed by Philippe Mouret in 1987 [15], and within five years, the laparoscopic approach was established as a feasible alternative to open cholecystectomy. Few surgeons attempting this exciting new technique had seen a laparoscopic cholecystectomy but were eager to start with it nonetheless [14]. The assumption that the technical skills derived from open surgery and knowledge of the operating area would transfer to the laparoscopic environment proved to be untrue as the ratio and severity of bile duct lesions increased after its hazardous introduction into surgical practice $[16,17]$.

Laparoscopic surgery may appear to be a modern type of surgery in many respects. In contrast, however, early training for this modern technique has been very traditional, exposing patients to an increased chance of serious injury. Over time, however, laparoscopic cholecystectomy became the gold standard for uncomplicated cholecystolithiasis [18].

Surgeons of the younger generation taught by the initial early adopters of the laparoscopic technique currently are better acquainted and more comfortable with the laparoscopic procedure than the open approach [19]. Ideally, they have overcome the asymptote of their learning curve for this specific type of surgery outside the operating room, but in general, this is not the case. Ideally, residents' competence is evaluated properly before they engage laparoscopic surgery independently. But again, this still is far from customary [20-22].
Fortunately, both surgeons and surgical residents do subscribe to the importance of training and examining laparoscopic procedural skill outside the operating theatre $[14,23,24]$. Why then is it so difficult to get people trained to achieve a minimal level of competency outside the operating room before they engage in surgery?

\section{Problems and pitfalls for laparoscopic training outlined}

Adopting competency frameworks

Information about the validity of CanMEDS in an international context is sparse, and little is known about how the aspects of the seven roles apply to various stages of trainees' development into specialists [25]. A rational internal validation was called for but cannot not be found in literature to date. In fact, little is known about the surgeon's perception of competence. Although technical proficiency definitely is considered an important prerequisite for a successful outcome, other qualities such as intellectual abilities, personality, communication skills, and a commitment to practice are important elements in the profile of a competent endoscopic surgeon. Not much is known about the relative contribution of each role to surgical competency [26]. A recent study by Chou et al. [27] showed that program directors are neutral or even concerned about how the CanMEDS roles other than the central role of medical expert are to be evaluated in their programs.

In addition to program directors, residents' knowledge of CanMEDS itself is limited. Residents' familiarity with the set of competencies appears to be quite limited, and knowledge about definitions of the roles is scarce [28]. The importance of being competent in all the roles required for a surgeon to be a competent is not appreciated by trainees [26] despite evidence showing that nontechnical competence (roles of communication, collaboration within a team) is the most important factor for patient safety and prevention of legal claims [29, 30]. Residents incorrectly perceive the central medical expert role as the most relevant and important competency, falsely believing that it represents the acquisition of medical and scientific knowledge [28].

Current training is not believed to ensure competence in all roles, nor do surgeons believe it ensures achievement of competency in every CanMEDS role [26]. Moreover, the framework's relevance itself has been questioned, and confusion exists about the overlapping nature of the roles. Furthermore, a variety of nonvalidated assessment tools appear to be of use in addressing the various CanMEDS roles [27].

At best, it might be concluded that an apparent distortion of the original CanMEDS construct from its original 
holistic philosophy exists within the surgical community. This is a genuine threat to any competency framework acceptance for surgical training. Without an understanding of the concepts, how can a competency framework gain credits for implementation? Moreover, how can issues such as standardization of competency measurement and accreditation be handled?

\section{Training outside the operating room}

Any form of surgical training, inside or outside the operating room, is time consuming, costly, and of variable effectiveness. As mentioned previously, surgical organizations are calling for methods to ensure the development and maintenance of skills, advance surgical training, and credential surgeons as competent [31].

Training by use of a virtual reality simulator is an option for supplementing standard training with the use of box trainers (limited in fidelity) or porcine in vivo or ex vivo setups (high in fidelity, but costly and controversial) in a surgical training curriculum. Indeed, virtual reality simulators are promising and potent tools for training residents in laparoscopy and endoscopy [32-35]. They enable trainees to perform standardized, reproducible virtual laparoscopic and endoscopic procedures ranging from basic task drills to full laparoscopic and endoscopic procedures with varying patient scenarios.

Simulators provide trainees with immediate, structured, objective feedback after each repetition, allowing performance to be tracked over time or compared with a benchmark often set by experts [36-38].Virtual reality training systems are intended to create new experiential learning opportunities that can serve as safe and effective alternatives to more traditional learning venues, such as the clinical operating room [32].

A recent systematic review of randomized controlled trials on the effectiveness of virtual reality training for laparoscopic surgery showed that such training resulted in a greater reduction in operating time, error, and unnecessary movements than standard non-virtual reality laparoscopic training [39]. Multiple studies have shown that skills acquired by simulation-based training are transferable to the operative setting [22, 33, 40, 41]. Worldwide, the belief is growing that virtual reality simulator training is an indispensable component of diverse endoscopic surgical training curricula [42], and is likely eventually to be a mandatory component of residency training in the surgical specialities [43-46].

A recent randomized controlled trial by Snyder et al. [47] showed that proctored instruction using virtual reality simulators does not offer any advantages to trainees in terms of achieving expert level proficiency with laparoscopic and endoscopic simulators. It is stated that the independent approach may be preferable for surgical residency programs desiring to implement virtual reality simulator training. This finding suggests that self-directed repetitive practice rather than expert instruction is the driving factor for simulator proficiency. Furthermore, development of skill is likely to be augmented by reviewing recordings of one's earlier attempts [48].

In the end, surgical trainees need a simulator proved to be valid by methodically sound studies and also proved to be valid for the course/curriculum in which it is used. Not embedding simulators in a curriculum essentially means no use of a simulator whatsoever [45].

Given the challenges of meeting surgical education requirements within the resident duty hour restrictions currently in place in the United States, Canada, and Europe, the independent but embedded approach may represent an optimal method for integrating simulator training into surgical residency programs. Electronic, open-platform surgical portfolios capable of online integration of training results with virtual reality simulators are key for easy surgical monitoring of technical competence.

\section{Cost effectiveness of training}

From the societal perspective, laparoscopic surgery saves money, but from a hospital point of view, the open operation often is less costly than its laparoscopic alternative [49-54]. Hospitals do not have economic incentives to adopt new technology because benefits accrue not to the hospital but to the insurance sector or the patients' employer. Patients, however, usually gain from the laparoscopic variant of a surgical procedure in terms of less pain, shorter hospital stay and recovery time, and better cosmesis.

Ultimately, patients undergoing elective surgery may not want to have surgery at centers not offering laparoscopic surgery for their problem or at centers not known as experienced in this area. Insurance companies may not agree to pay for operations unless centers are visibly labeled as having expertise in the area. Such centers may have to show the number of procedures performed, complication rates, and certified training programs followed by the surgeons working in it.

It might be appropriate to invest in training surgeons and their operating team for specific laparoscopic procedures. Competency-based training not only shortens operation time (hospital incentive) but ultimately increases patient safety (both a patient and a hospital incentive) and certifies surgeons that have successfully followed such a course. Insurance or governmental support and monitoring are important factors in selecting and funding such hospitals 
and training curricula. Moreover, governments that do not allow surgical procedures to be performed in centers that offer no credible information on the laparoscopic surgical competency of residents might speed up the process of implementing valid training initiatives tremendously.

\section{Conclusions and recommendations}

In conclusion, much work needs to be done before the claim that CanMEDS is an accepted accreditation standard with regard to objectives of training, final in-training evaluations, exam blueprints, and maintenance of certification can be considered truly legitimate in laparoscopic surgery. Competency-based curricula for key laparoscopic procedures need to be developed. National or European societies must determine which procedures are in fact key to be mastered by surgical residents and in which phase of their education.

In these specific training curricula, CanMEDS roles need to be stated clearly, addressed specifically, and tailored appropriately for the particular procedure. Team training that focuses on the roles of communicator and collaborator in the operating room must be addressed. Knowledge of the procedure may be transferred by proctored instruction, but the electronic open portfolio might be very useful in administering and examining the use of multimodality E-learning modules. Technical skill training must be embedded in a curriculum, allowing for repetitive practice.

Examination of such a curriculum needs different examination instruments. Knowledge may be examined using questionnaires. A promising type of knowledge testing uses comprehensive integrated puzzling (CIP), which eliminates the element of chance known to be present in multiple-choice examinations. Technical surgical skill must be assessed objectively using validated examination procedures. Objective surgical assessment of technical skills (OSATS) examination stations may be developed for the specific procedure; or performance can be evaluated by validated procedure-specific virtual reality simulators. A patient management examination (PAME) needs to be integrated into the exam. A PAME uses simulative patients in a patient setting, demanding mastery of the clinical outpatient setting by the examination candidate.

This type of examination is needed to verify the mastery of competencies such as being competent in the roles of communicator, collaborator, health advocate, manager, scholar, and professional [55]. Residents should not be allowed to operate on patients unsupervised unless they are proven competent by having successfully passed at least their technical surgical skills examinations. Surgical residents that excel in one area of competence but lack in other competencies may need to shift priorities in their training curriculum. Examinations are therefore indispensable and may function to tailor the curriculum even further to each individual.

Only when aforementioned conditions are met can a curriculum truly produce the medical experts that our society demands, and most importantly, that our patients need.

Acknowledgements Disclosures M. P. Schijven and W. A. Bemelman have no conflicts of interest or financial ties to disclose.

Open Access This article is distributed under the terms of the Creative Commons Attribution Noncommercial License which permits any noncommercial use, distribution, and reproduction in any medium, provided the original author(s) and source are credited.

\section{References}

1. Evans RG (2003) Witnesses to 20th-century medicine, a professor "honorarius": an Australian experiment in medical administration, 1939-1964. Health Hist 5:115-138

2. Clowes W (1596) A profitable and necessarie booke of observations. Bollifant, London

3. Baron JH (2005) End piece: God, surgeon, medicine patient. BMJ 330:455

4. Leape LL (1994) Error in medicine. JAMA 272(23):1851-1857

5. Kohn LT, Corrigan JM, Donaldson MS (1999) To err is human: building a safer health care system. National Academy Press, Washington, DC

6. Zelenock GB, Zambricki CS (2001) The health care crisis: impact on surgery in the community hospital setting. Arch Surg 135: $585-591$

7. Frank JR, Bernard Langer OC (2003) Collaboration, communication, management, and advocacy: teaching surgeons new skills through the CanMEDS project. World J Surg 27:972-978

8. Royal College of Physicians and Surgeons of Canada (2007) The CanMEDS physician competency framework. Better standards, better physicians, better care. http://rcpsc.medical.org/canmeds/ index.php. Accessed 5 Jan 2010

9. Accreditation Council for Graduate Medical Education. ACGMEoutcome project; Educating physicians for the 21st century: A 4 module educational resource for teaching and learning the competencies. http://www.acgme.org/Outcome/ and http://www. acgme.org/outcome/e-learn/e_powerpoint.asp. Accessed 9 Jan 2010

10. Scheele $F$ et al (2008) Introducing competency-based postgraduate medical education in the Netherlands. Med Teach 30: 248-253

11. Koninklijke Nederlandsche Maatschappij tot Bevordering der Geneeskunst (2009) Modernisering Medische Vervolgopleidingen, Utrecht, the Netherlands. http://knmg.artsennet.nl/Opleidingen-Registratie/modernisering.htm. Accessed 5 Jan 2010

12. Hamming J, Borel Rinkes I, Heineman E (2008) Scherp (Structure Curriculum Heelkunde voor Reflectieve Professionals). Opleidingsplan Heelkunde (Sharp, Structure Curriculum Surgery for Reflective Professionals. Educational Plan Surgery). http:// knmg.artsennet.nl/web/file?uuid=e9ca357d-dab2-4a93-9c8e-549a77 e2c647\&owner=db8aa948-9eba-4439-afc5-dedd737f7886. Accessed 5 Jan 2010 
13. Grantcharov T, Reznick RK (2009) Training tomorrow's surgeons: what are we looking for and how can we achieve it? ANZ J Surg 79:104-107

14. Aggarwal R, Moorthy K, Darzi A (2004) Laparoscopic skills training and assessment. BJS 91:1549-1558

15. Liityaski GS (1999) Mouret, Dubois, and Perissat: the laparoscopic breaktrough in Europe. JSLS 3:163-167

16. MacFadyen BV et al (1998) Bile duct injury after laparoscopic cholecystectomy. Surg Endosc 12:315-321

17. The Southern Surgeons Club (1991) A prospective analysis of 1, 518 laparoscopic cholecystectomies. N Eng J Med 324:1073-1078

18. Sauerland S et al (2006) Laparoscopy for abdominal emergencies: evidence-based guidelines of the European Association for Endoscopic Surgery. Surg Endosc 20:14-29

19. Zaraca $F$ et al (1995) Senior versus proctored young and resident surgeons' experience in laparoscopic cholecystectomy: is there any need of previous exposure to open biliary surgery? J Laparoendosc Surg 5:303-307

20. Schijven MP, Berlage JTM, Jakimowicz J (2004) Minimal access surgery training in the Netherlands: a survey among residents-intraining for general surgery. Surg Endosc 18:1805-1814

21. Schijven MP (2005) Virtual reality simulation for laparoscopic cholecystectomy: the process of validation and implementation in the surgical curriculum outlined. University of Leiden, the Netherlands, Thesis, p 180. ISBN: 90-9019048-1

22. Schijven MP et al (2005) The Eindhoven laparoscopic cholecystectomy training course: improving operating room performance using virtual reality training: results from the first EAESaccredited virtual reality training curriculum. Surg Endosc 19: $1220-1226$

23. Schout BM et al (2008) Is endoscopic skills training in a skills laboratory necessary? Perceptions of urology programme directors in the Netherlands. BJU Int 102:1362-1363

24. Schijven MP et al (2008) Perceptions of surgical specialists in general surgery, orthopaedic surgery, urology and gynaecology on teaching endoscopic surgery in The Netherlands. Surg Endosc 22:472-482

25. Ringsted C et al (2006) Are some of the challenging aspects of the CanMEDS roles valid outside Canada? Med Educ 40: 807-815

26. Arora $\mathrm{S}$ et al (2009) What makes a competent surgeon? Experts' and trainees' perceptions of the roles of a surgeon. Am J Surg 198:726-732

27. Chou $\mathrm{S}$ et al (2008) CanMEDS evaluation in Canadian postgraduate training programmes: tools used and programme director satisfaction. Med Educ 42:879-886

28. Zibrowski EM et al (2009) The sum of the parts detracts from the intended whole: competencies and in-training assessments. Med Educ 43:741-748

29. Way LW et al (2003) Causes and prevention of laparoscopic bile duct injuries: analysis of 252 cases from human factors and cognitive psychology perspective. Ann Surg 237:460-469

30. Vincent C, Moorthy K, Phillips A (1994) Why do people sue doctors? A study of patients and relatives taking legal action. Lancet 343:1609-1613

31. Roberts KE, Bell RL, Duffy AJ (2006) Evolution of surgical skills training. World J Gastroenterol 12:3219-3224

32. Seymour NE (2008) VR to OR: a review of the evidence that virtual reality simulation improves operating room performance. World J Surg 32:182-188

33. Sturm LP et al (2008) A systematic review of skills transfer after surgical simulation training. Ann Surg 284:166-179

34. Gurusamy KS et al (2009) Virtual reality training for surgical trainees in laparoscopic surgery. Cochrane Database Syst Rev 1 (4 CD006575)
35. Schijven M (1994) Virtual reality simulation for laparoscopic cholecystecomy: the process of validation and implementation in the surgical training curriculum outlined. University of Leiden, Leiden

36. Gorman PJ et al (2000) The future of medical education is no longer blood and guts, it is bits and bytes. Am J Surg 180: 353-356

37. Grantcharov TP et al (2001) Virtual reality computer simulation: an objective method for the evaluation of laparoscopic surgical skills. Surg Endosc 15:242-244

38. Schreuder HW et al (2009) Face and construct validity of virtual reality simulation of laparoscopic gynecologic surgery. Am J Obstet Gynecol 200:540.e1-540.e8

39. Gurusamy K et al (2008) Systematic review of randomized controlled trials on the effectiveness of virtual reality training for laparoscopic surgery. Br J Surg 95:1088-1097

40. Gallagher AG et al (2002) From VR to OR: a prospective, randomized, double-blind controlled trial of virtual reality (VR) training for operating room (OR) performance of laparoscopic cholecystectomy. From the Tenth International Congress of the European Association for Endoscopic Surgery. Centro de Congressos de Lisboa, Portugal

41. Grantcharov TP et al (2004) Randomized clinical trial of virtual reality simulation for laparoscopic skills training. Br J Surg 91: 146-150

42. Drăghici I et al (2009) Laparoscopic training: the guarantee of a future in pediatric surgery. Chirurgia Bucur 104:255-258

43. Vlaovic PD, McDougall EM (2006) New age teaching: beyond didactics. Sci World J 8:2370-2380

44. Chang $L$ et al (2007) Integrating simulation into a surgical residency program: is voluntary participation effective? Surg Endosc 21:418-421

45. Dongen KW et al (2008) Virtual reality training for endoscopic surgery: voluntary or obligatory? Surg Endosc 22:664-667

46. Ahlberg G et al (2005) Virtual reality colonoscopy simulation: a compulsory practice for the future colonoscopist? Endoscopy 37:1198-1204

47. Snyder CW et al (2009) Proficiency-based laparoscopic and endoscopic training with virtual reality simulators: a comparison of proctored and independent approaches. J Surg Educ 66:201-207

48. Jamshidi $\mathrm{R}$ et al (2009) Video self-assessment augments development of videoscopic suturing skill. J Am Coll Surg 209:622-625

49. Sporn E et al (2009) Laparoscopic appendectomy: is it worth the cost? Trend analysis in the US from 2000 to 2005. J Am Coll Surg 208:179. e2-185. e2

50. Hernández RA et al (2008) Systematic review of economic evaluations of laparoscopic surgery for colorectal cancer. Colorectal Dis 10:859-868

51. Jönsson B, Zethraeus N (2000) Costs and benefits of laparoscopic surgery: a review of the literature. Eur J Surg 166:48-56

52. Berggren U et al (1996) A cost-minimization analysis of laparoscopic cholecystectomy versus open cholecystectomy. Am J Surg 172:305-310

53. Kald A et al (1997) Surgical outcome and cost-minimization analysis of laparoscopic and open hernia repair: a randomized prospective trial with one year follow up. Eur J Surg 163:505-510

54. McCormack K et al (2005) Laparoscopic surgery for inguinal hernia repair: systematic review of effectiveness and economic evaluation. Health Technol Assess 9:1-203, iii-iv

55. Schijven MP et al (2009) Transatlantic comparison of the competence of surgeons at the start of their professional career. $\mathrm{Br} \mathrm{J}$ Surg 97(3):443-449 